IOSR Journal of Pharmacy

ISSN: 2250-3013, www.iosrphr.org

||| Volume 2 Issue 5 ||| Sep-Oct. 2012 ||| PP.21-25

\title{
Self medication among patients seen at ophthalmology clinics at four hospitals in dar es salaam tanzania
}

\author{
Godeliver A.B. Kagashe ${ }^{1}$, Bumbuli Msela ${ }^{2}$ \\ Department of Pharmaceutics, School of Pharmacy, Muhimbili University of Health and allied \\ Sciences Dar es SalaamTanzania
}

\begin{abstract}
Self medication practices with eye medicines among patients attending eye clinics and factors that lead to self-medicate were assessed. Patients visiting eye clinics were interviewed with the aid of a structured questionnaire composed of closed and open ended questions.

A total of 358 respondents were interviewed. Among these $59.8 \%$ admitted to have used eye medicines before coming to hospital. Eighty eight percent $88.6 \%$ used modern medicines, $3.4 \%$ used traditional medicines and $7 \%$ used both modern and traditional medicines. Traditional eye medicines used were in liquid form, of which $68 \%$ were from plant sources, $16 \%$ salty water and $16 \%$ honey. The major sources of the eye medicines used were from pharmacies $41.6 \%$, and hospitals 33\%. Only 24.3\% of respondent knew the names of the medicine used. Of the medicines used $66.7 \%$ were antibiotics. Fifteen percent $15.4 \%$ of respondents experienced side effect after self medication including blindness. Main factors influencing self medication were living far from hospital, and high cost of treatment in the formal health care facilities.

It is concluded that self medication with eye medicines is common among the population interviewed. Health education on appropriate medicine use and dangers of using eye medicines without professional advice is needed.
\end{abstract}

Keywords—eye medicines, ocular problems, rational use, self medication, traditional medicine

\section{INTRODUCTION}

Self-medication has been defined by World health Organization (WHO) as the selection and use of medicines by individuals to treat self-recognized illnesses or symptoms [1] Self-medication is also defined as obtaining and consuming one or more drug(s) without the advice of a physician either for diagnosis, prescription or surveillance of the treatment [2].

Prevalence of self medication in different population groups has been studied. Awald et al in 2006 reported high prevalence $81 \%$ of self medication in urban areas of Khartoum [3]. James et al found that about $58 \%$ of students at the Arabian Gulf University practiced self medication [4] Shveta et al reported that about $73 \%$ of the studied population in Punjab self medicated with food supplements [5]. Abahussain demonstrated a prevalence of $92 \%$ of self medication among the adolescents in Kuwait [6]. Self medication in specific groups of patients has also been assessed in patients with dermatological problems [7]. In patients with ocular problems however few studies on self medication have been reported [8,9]. People self medicate with both prescription and non prescription medicines as a result irrational use of medicines in the course of self medication is high. In Tanzania not much has been reported about self medication with eye medicines. This study therefore, wanted to determine the prevalence of self medication practices among patients with ocular problems, factors influencing self medication, the side effects encountered and whether the medicines are used rationally.

\section{METHODOLOGY}

The study was a descriptive cross-sectional study, which was conducted at four health facilities from November 2010 to June 2011. Hospitals were conveniently selected because of easy accessibility and attendance of patients to eye clinics. A total of 358 Patients visiting the eye clinics were interviewed using a questionnaire. The questionnaire consisted of open and closed ended questions aiming at finding out whether the patient practiced self medication, factors influencing self medication, the side effects encountered, sources of medication used for self medication and whether the medicines are used rationally

Ethical clearance was obtained from Muhimbili University of Health and allied Sciences (MUHAS) Ethical Review Committee. Letters requesting permission to conduct the study at the clinics were sent to the respective hospitals. After obtaining permission, the researcher visited the clinics and collected data by interviewing patients. Patients were given a short introduction to the study and told the purpose of the study. 
They were assured that the information given would be kept confidential. Patients were then asked verbally whether they were willing to participate or not. Those who agreed were then interviewed.

Data from the questionnaires was entered into computer software and analyzed using statistical package for social sciences (SPSS), version, 16.0

\section{RESULTS}

A Total of 358 patients were interviewed and 59.8\% reported to self medicate before coming to the eye clinic. Demographic features of respondents are shown in Table 1

Regarding the type of medicine used, about $88.6 \%$ used modern medicines while $3.4 \%$ used traditional medicines and $7 \%$ used both traditional medicines and modern medicines.

Fig. 1 shows the type of modern medication used for self medication. Antibiotics were the most used type of medicines.

The respondents obtained the medications from different sources. These are shown in Fig. 2. Pharmacies were places where most of respondents $(41.6 \%)$ obtained their medicines.

Ocular problems that led respondents to use eye medicines are shown in Table 2 . The most mentioned condition was paining eyes $(47.7 \%)$, Itchy eyes $(26.6 \%)$ and poor vision $(30.4 \%)$.

Majority of the respondents $(61.7 \%)$ could not remember names of medicines used, only $24.3 \%$ remembered the name. The names of medicines used are shown in Table 3.

Fifteen percent $(15.4 \%)$ of respondents experienced side effect after self medication. Table 4 shows the different side effects experienced. Inflammation of the eye, increased irritation, excessive tears, and blindness were among the side effects experienced by respondents. All respondents who became blind had used traditional eye medicines of plant origin. Table 5 shows factors that influenced respondents to self medicate. Living far from hospital (28\%) and advice from family members $(22.5 \%)$ were the major influencing factors.

\section{DISCUSSION}

The present study has shown that about $59.8 \%$ of respondents used eye medicines before coming to hospital. Self medication by people with ocular problems has been reported in several studies $[10,11,12]$. Eye problems that led to self medication are shown in table 2. Itchy eyes was mentioned as one of the problems, similar findings were reported in a study done by Tayanithi et al where people with itchy eyes and those with red eyes self medicated more [8]. When asked whether there was improvement after self medication most respondents said no and that is why they had to come to the hospital.

Regarding the type of medicine used, about $88.6 \%$ used modern medicines while $3.4 \%$ used traditional medicines and $7 \%$ used both traditional medicines and modern medicines. Among those who used modern medicines, only $(24.3 \%)$ knew the name of the medicine used. Not knowing the name of medicine used by patients who practice self medication was also reported in a study by Ferreira de Moraes [13] This puts the health worker in a difficult position when trying to help the patient as he/she may not know whether the drug taken may interact with the one he/she is going to prescribe.

For those who used modern medicines it was revealed that $66.7 \%$ of the medicine used were antibiotics, Fig.1. This might be due to a belief that most of the eye problems are due to bacterial infections, but from the patient's records (patient's files), it was found that, the common diseases were allergic conjunctivitis, refraction, cataract, optic neuropathy, corneal laceration, and glaucoma, most of which do not require antibiotics. This implies that in most cases antibiotics were misused. Use of antibiotics to self medicate has been reported in other studies $[14,15,16]$. People self medicate with both prescription and non prescription medicines as a result irrational use of medicines in the course of self medication is high. Antibiotics are prescription only medicines, using them without a physician's advice is irrational.

In Tanzania almost every pharmacy sells medicines without a prescription [17] this may make it easy for patients to access the antibiotics since from the present results the major source of medicines for self medication was from pharmacies Fig.2. Several studies have reported community/private pharmacies as the main source of medicines used for self medication [14,18]. Thirty percent of respondents said they used medicines from the hospital these medicines were obtained from the previous hospital visits. This may mean patients did not take their doses properly or if the medicines have been kept for a long time patients could be using medicines that have already expired.

Traditional medicines used were in liquid form, of which $68 \%$ were from plant sources, $16 \%$ was salty water, and $16 \%$ honey. The washing of eyes with substances derived from plants may cause permanent damage to the eye such as the one resulting from fungal infections [9]. Use of salt water was also reported in a study by Carvalho et al [9] however he cautions that the use of saline is contraindicated in some ocular conditions. Seven percent $(7 \%)$ of respondent used both modern and traditional eye medicines. this may lead to patient experiencing drug interaction unknowingly. 
Most respondents (41.6\%) obtained their medicines from the pharmacies Fig.2, this might be due to the fact that patients prefer pharmacies as sources of medicines because they are easily accessible in many areas of Dar es salaam. Pharmacies have been shown to be the first stop for people seeking health care and the reasons for this are said to be easy accessibility, cheap, no consultation fee. Some of the respondents in this study said they had no money to visit hospitals.

Factors that were mentioned by respondents to influence self medication are shown in Table 4. Living far from the health facility, advice from family members, high cost of treatment in hospitals, and long time of waiting at the hospital were the main influencing factors.

Fifteen percent of respondents experienced side effects these are shown in Table 5. Six percent (6\%) went blind after applying traditional eye medicines. Use of traditional eye medicines is discouraged as it has been shown to cause blindness and other ocular complications by other researchers $[11,12]$. Further analysis of the data showed an association between the level of education and self medication with eye medicines. The proportion of patients who used drug before coming to hospital decreased from $(71.7 \%)$ for those who did not have formal education to $(41.0 \%)$ among those who attained higher education. With the P-value (0.007), this was statistically significant.

These results are different from study by Shiveta [5] who reported that those who were educated practiced self medication more.

Studies done on self-reported prevalence of illnesses that prompted self-medication have shown that cough/cold/influenza, digestive disorders, accidental injuries, headache/dizziness, anxiety/insomnia, skin problems, asthma, liver disease, fever, boils were the prevalent health problems that prompted self medication $[4,19]$. The present study shows that people with eye problems also practice self medication. This practice is very risky given that the eye is a very delicate organ and using the wrong medication on the eye may lead to bad consequences like blindness.

\section{CONCLUSION}

Self medication with eye medicines was common among patients with ocular problems. Antibiotics were the most used type of medicine and they were used irrationally. Pharmacies were the major source of medicines for self medication. It is recommended that health education should be given to patients on the appropriate use of medicines in self medication and dangers of using eye medicines without professional advice. In addition rules and regulations on dispensing of medicines from private pharmacies should be reinforced such that prescription only medicines will be dispensed upon presentation of a prescription, and over the counter medicines will be dispensed for the right indication.

\section{REFERENCES}

[1]. World Health Organization/Drug Action Program (WHO/DAP). Public Education in Rational Drug Use; Report of an Informal Consultation, 23-26 November 1993, Geneva.

[2]. Montastruct JL, Bagheri H, Geraud T, and Lapeyre-Mestre, M. Pharmacovigilance of Self-medication. Therapie, 52(2) 1997, 105-110.

[3]. Awad AI, Eltayeb IB. Self-medication practices with antibiotics and antimalarials among Sudanese undergraduate university students. Ann Pharmacother. 41(7) 2007, 1249-55.

[4]. James H, Handu SS, Khaja KA, Sequeira RP. Influence of medical training on self-medication by students. Int J Clin Pharmacol Ther, 46 (1), 2008, 23-9.

[5]. ShvetaS, Jagmohan S, A study of self medication patterns in Punjab Indian Journal of Pharmacy Practice, 4(2,) 2011, 43-46

[6]. Abahussain E, Matowe LK, Nicholls PJ. Self-Reported Medication Use among Adolescents in Kuwait. Med Princ Pract; 14, 2005, 161-164

[7]. Mouh ari-Toure A, Kombaté K, Saka B, Akakpo S, Boukari OB, Pitche P, Tchangaï-Walla K. Self-medication for

[8]. Tayanithi P, Aramwit P Self medicated over the counter ophalmic solutions in central Bangkok. J.Med.Assoc Thai, 88(4) 2005, S330-4

[9]. Carvalho RS, Kara-Jose N, Temporin ER, Kara-Junior Noma-Campos R. Self medication initial treatments used by patients seen in an ophthalmology emergency room. Clinics 68(8), 2009, 735-741

[10]. Fasina O, Ubah JN. Pattern of pre-hospital consultation among ophthalmic patients seen in a tertiary hospital in South West Nigeria. Afr J Med Med Sci. 38(2), 2009, 173-7

[11]. Eze BI, Chuka-Okosa CM, Uche JN. Traditional eye medicine use by newly presenting ophthalmic patients to a teaching hospital in south-eastern Nigeria: socio-demographic and clinical correlates. BMC Complement Altern. Med, 9, 2009, 40.

[12]. Ukponmwan CU, Momoh N. Incidence and complications of traditional eye medications in Nigeria in a teaching hospital. Middle East Afr J Ophthalmol. 17(4), 2010, 315-9.

[13]. Ferreira de Moraes AC, Delaporte TRM, Molena -Fernandes CV, Falcaol MC. Factors associated with medicine use and self medication are different in adolescents Clinics (Sao Paulo,) 66(7), 2011, 1149-1155

[14]. Berzanskyte A, Valinteliene R, Haaijer-Ruskamp FM, Gurevicius R, Grigoryan L.Self-medication with antibiotics in Lithuania. Int J Occup Med Environ Health, 19(4), 2006, 246-53. 
[15]. Al-Azzam SI, Al-Husein BA, Alzoubi F, Masadeh MM, Al-Horani MA.Self-medication with antibiotics in Jordanian population. Int J Occup Med Environ Health. 20(4), 2007, 373-80.

[16]. Sawlha, A F, Selfmedication with antibiotics a study in Palestina. The int J. of Risks and Safety in Medicine, 20(4,) 2008, 213-222

[17]. Kagashe GAB, Minzi O, and Matowe L, An assessment of dispensing practices in private pharmacies in Dar es Salaam Tanzania. International Journal of Pharmacy Practice.19, 2010, 30-35

[18]. Togoobaatar G, Ikeda N, Ali M, Sonomjamts M, Dashdemberel S, Mori R, Shibuya K.Survey of non-prescribed use of antibiotics for children in an urban community in Mongolia. Bull World Health Organ, 88(12), 2010, 930-6.

[19]. Fuentes Albarrán K, Villa Zapata L. Analysis and quantification of self-medication patterns of customers in community pharmacies in southern Chile. Pharm World Sci. 30(6), 2008, 863-8..

Table1. Demographic variables of the respondents

\begin{tabular}{|lcc|}
\hline VARIABLES & PERCENT & FREQUENCY \\
\hline SEX & 187 & \\
Male & 171 & 52.2 \\
Female & & 47.8 \\
EDUCATION & 46 & \\
None & 153 & 12.8 \\
Primary & 120 & 42.7 \\
Secondary & 39 & 33.5 \\
High education & & 10.9 \\
AGE & 59 & 16.5 \\
$<20$ years & 155 & 43.3 \\
21-40 years & 94 & 26.3 \\
41-60 years & 50 & 14.0 \\
61+years & & \\
\hline
\end{tabular}

Table 2. Conditions that led to self-medication

\begin{tabular}{|l|l|}
\hline Condition & Percent (\%) \\
\hline Painful eyes & 47.7 \\
\hline Red eye & 6.1 \\
\hline Teary eyes & 25.7 \\
\hline discharge & 6.5 \\
\hline Itchy eyes & 26.6 \\
\hline Poor vision & 30.4 \\
\hline injury & 11.7 \\
\hline cataract & 6.1 \\
\hline Swelling of the eyes & 5.6 \\
\hline headache & 6.1 \\
\hline & \\
\hline & \\
\hline
\end{tabular}

Table 3. Names of medicines used

\begin{tabular}{|l|l|}
\hline Name of the medicine & Percent (\%) \\
\hline Chloramphenical ointment & 11.8 \\
\hline Dexamethasone eye drops & 7.8 \\
\hline Floxacin eye drops & 5.9 \\
\hline Tetracycline eye ointment & 11.8 \\
\hline Gentamycin eye drops & 7.8 \\
\hline Atropine eye drops & 14 \\
\hline Predinisolone eye drops & 2 \\
\hline Neomycin eye drops & 2 \\
\hline Boric acid & 7.8 \\
\hline Tetracycline eye drops & 6 \\
\hline injections & 2 \\
\hline & \\
\hline
\end{tabular}


Table 4. Factors influencing self medication

\begin{tabular}{|l|l|}
\hline Factor & Percent \\
\hline Living far from hospital & 28 \\
\hline Advice from family members & 22.5 \\
\hline Advice from family friends & 11 \\
\hline Long waiting time at the hospital & 11 \\
\hline High cost of treatment at the hospital & 8.5 \\
\hline Influency from Pharmacy & 6 \\
\hline Busy & 3.5 \\
\hline No reason & 20.5 \\
\hline
\end{tabular}

Table 5. Side effects experienced by respondents after self medication

\begin{tabular}{|l|l|}
\hline Side effect & Percent (\%) \\
\hline Increased pain & 38 \\
\hline Inflammation of the eye & 19 \\
\hline Increased irritation & 19 \\
\hline Excessive tearing & 9 \\
\hline Corneal ulceration & 9 \\
\hline blindness & 6 \\
\hline &
\end{tabular}

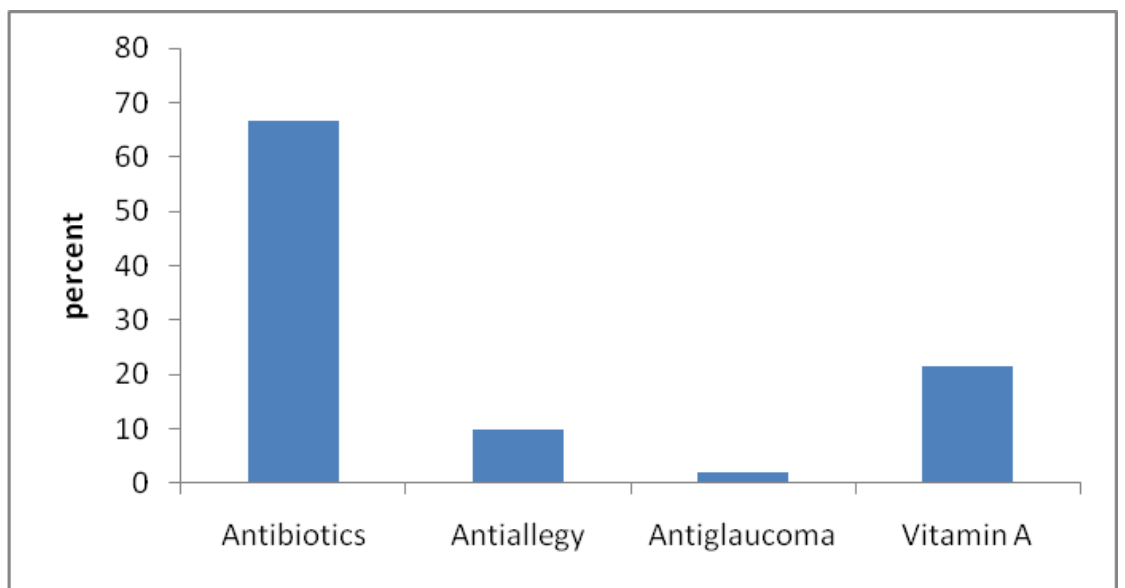

Figure 1. Category of medicines commonly used

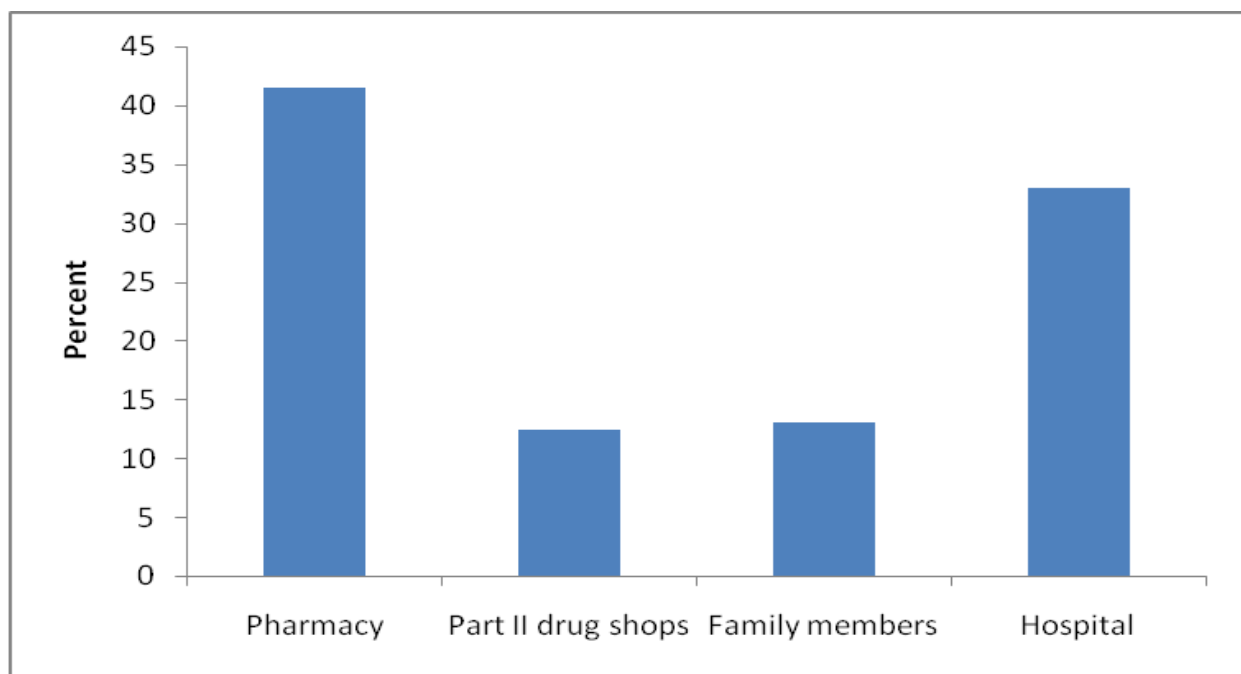

Figure 2. Sources of medicines used for self medication 